\title{
DESCARTE INADEQUADO DE MEDICAMENTOS: IMPACTOS NEGATIVOS AO MEIO AMBIENTE E À SAÚDE PÚBLICA ${ }^{1}$
}

\author{
Ilse de Lima Arruda Storel ${ }^{2}$
}

Neide Maria de Castilho ${ }^{3}$

\author{
Edilene Mayumi Murashita Takenaka ${ }^{4}$
}

\section{RESUMO}

O descarte doméstico de medicamentos realizado de forma inadequada traz uma preocupação constante no que tange ao meio ambiente. A contaminação do solo e da água decorrente destes fármacos dispostos em locais inadequados demanda atitudes efetivas que visem a redução dos impactos ambientais decorrentes. $\mathrm{O}$ objetivo do presente artigo foi discorrer sobre os danos causados ao meio ambiente pela prática inadequada de descarte de medicamentos. A população usuária de medicamentos deve ser esclarecida e conscientizada da importância do uso racional de medicamentos como sendo uma das medidas necessárias a diminuir as sobras decorrentes de aquisição desnecessária ou do não cumprimento do esquema terapêutico proposto, além de outras. A metodologia utilizada foi o levantamento de dados obtidos por meio de pesquisa bibliográfica que permitiu o contato com questões existentes e explorar novos conhecimentos sobre o assunto tratado.

PALAVRAS-CHAVE: Descarte inadequado. Medicamentos. Meio ambiente.

\footnotetext{
${ }^{1}$ Este trabalho faz parte das discussões realizadas durante a disciplina Políticas Públicas Ambientais e Gerenciamento de Resíduos oferecida no Mestrado em Meio Ambiente e Desenvolvimento Regional MMADRE da UNOESTE de Presidente Prudente - SP

${ }^{2}$ Docente da disciplina Saúde Coletiva no curso de Medicina - UNOESTE. Aluna especial na disciplina Políticas Públicas Ambientais e Gerenciamento de Resíduos Sólidos, do curso de Mestrado em Meio Ambiente e Desenvolvimento Regional - UNOESTE - ilce.storel@uol.com.br

${ }^{3}$ Docente da disciplina Saúde Coletiva no curso de Medicina - UNOESTE. Aluna especial na disciplina Políticas Públicas Ambientais e Gerenciamento de Resíduos Sólidos, do curso de Mestrado em Meio Ambiente e Desenvolvimento Regional - UNOESTE - neidecastilho@unoeste.br

${ }^{4}$ Docente da disciplina Políticas Públicas Ambientais e Gerenciamento de Resíduos Sólidos do curso de Mestrado em Meio Ambiente e Desenvolvimento Regional - UNOESTE - edilene@unoeste.br
} 


\title{
INADEQUATE DISCARD OF MEDICINES: NEGATIVES IMPACTS TO THE ENVIRONMENT AND PUBLIC HEALTH
}

\begin{abstract}
The discard of domestic medicines done in an inadequate way brings constant worries regarding the environment. The contamination of soil and water arising from those drugs disposed in inappropriate places require effective actions that aim the reduction of the resulting environmental impacts. The objective of this article is discuss about the damages done to the environment by the inadequate practice of discard of medicines. The medicine users must be clarified and made aware of the importance of rational use of medicines as an action necessary to reduce the leaves from unnecessary acquisition or not fulfillment of the therapeutic plan proposed, or other reasons. The methodology used was the collection of data obtained by bibliographic research that allowed contact with issues existing and explore new knowledge about the subject discussed.
\end{abstract}

keywords: Inadequate discard. Medicines. Environment.

\section{DISPOSICIÓN INADECUADA DE MEDICAMENTOS: IMPACTOS NEGATIVOS AL MEDIO AMBIENTE Y SALUD PÚBLICA}

\begin{abstract}
RESUMEN
La disposición interna de los medicamentos realizadas irregularmente una preocupación constante con respecto al medio ambiente. La contaminación del suelo y el agua resultante de estos fármacos dispuestos en lugares inapropiados exigen medidas eficaces destinadas a reducir los impactos ambientales. El objetivo de este trabajo fue abordar los daños causados al medio ambiente por la práctica inadecuada de la eliminación de la droga. El usuario de la población medicamentos debe ser informado y consciente de la importancia del uso racional de los medicamentos como una de las medidas necesarias para reducir los excedentes derivados de la compra innecesaria o para cumplir con el régimen de tratamiento propuesto, y otros. La metodología utilizada fue los datos de la encuesta obtenidos por medio de la literatura que permitieron el contacto con los problemas existentes y explorar nuevos conocimientos sobre el tema.
\end{abstract}

PALABRAS-CLAVE: Desechar inapropiado. Drogas. Medio Ambiente. 


\section{INTRODUÇÃO}

A ONU (Organização das Nações Unidas) no documento intitulado "Relatório Mundial sobre Drogas/2013" observa que houve uma estabilidade no uso de drogas tradicionais e aponta o aumento alarmante de novas substancias psicoativas consumidas no Brasil e no mundo.

Tal ampliação no consumo desses medicamentos pode ser resultado de melhores condições de acesso a informações e também aos tratamentos oferecidos pela indústria farmacêutica para grande parte da população que necessita do auxílio medicamentoso. Entretanto, os medicamentos vencidos ou as sobras de tratamento não podem ser descartados de qualquer maneira, sem se ter maiores preocupações com o impacto que isto pode causar ao meio ambiente.

Apesar das legislações e regulamentações existentes que apresentam como objeto a destinação adequada do produto, existem duas situações apontadas como críticas:

a) o descarte inadequado feito pelos domicílios que é agravada pelo hábito do estoque caseiro e pelo crescente consumo de medicamentos pela população brasileira e;

b) o não-cumprimento de determinações legais por autoridade públicas relativas ao descarte de medicamentos.

O objetivo do presente artigo foi discorrer sobre os danos causados ao meio ambiente pela prática inadequada de descarte de medicamentos.

\section{DESCARTE DE MEDICAMENTOS: um breve esclarecimento}

Segundo Alvarenga e Nicoletti (2010) a legislação existente sobre o descarte de medicamentos é direcionado aos estabelecimentos de saúde e não engloba a população em geral.

Tal fato dificulta o entendimento sobre os impactos decorrentes do descarte doméstico, no qual a população elimina os medicamentos no lixo comum gerando 
resíduos que são inadequadamente dispostos e podem gerar sérios danos ambientais.

Conforme Rodrigues (2009, p.80), "vale ressaltar que a realidade sanitária do país, com infraestrutura precária, ausência de aterros sanitários, é outro fator que dificulta o tratamento adequado de resíduos de natureza biológica ou química."

De acordo com Gasparini, Gasparini e Frigieri (2011) o destino dos medicamentos que sobram de tratamentos finalizados e dos que são comprados em quantidades desnecessárias são, costumeiramente, guardados para serem utilizados novamente trazendo outro grave problema à saúde pública: a automedicação.

Gasparini, Gasparini e Frigieri (2011) acrescentam ainda, que o descarte inadequado é feito pela maioria das pessoas por falta de informação e divulgação sobre os danos causados pelos medicamentos ao meio ambiente e por carência de postos de coleta. Dessa forma, a população é a peça chave na solução dos problemas causados pelos medicamentos quando inadequadamente descartados.

Faz-se necessário todo um trabalho de educação e conscientização ambiental para que essa população tenha acesso à informações ambientalmente corretas para que possa exercer, de forma plena, a defesa da sustentabilidade.

Grande parte da população brasileira não tem consciência acerca dos malefícios que as substâncias químicas presentes nos restos de medicamentos descartados em pias, vasos sanitários ou mesmo no lixo doméstico podem causar à Natureza a partir do contato com a água, o solo e a atmosfera.

Sotoriva (2009) afirma que a falta de informação faz com que as pessoas descartem esses medicamentos no lixo comum ou em vasos sanitários, porém, o sistema de esgoto brasileiro não está preparado para fazer o tratamento adequado de resíduos tóxicos provenientes de medicamentos que são atirados na pia ou no vaso sanitário.

Nascimento (2008) relata que o descarte inadequado de medicamentos vencidos pode causar sérias intoxicações no ser humano e também ao meio ambiente, pois os remédios têm componentes resistentes que se não forem tratados acabam voltando para a nossa casa e a gente pode até consumir água com restos de remédios. 
De acordo com Alvarenga e Nicoletti (2010) o Brasil está entre os maiores consumidores mundiais de medicamentos o que contribui para o aumento nas sobras de medicamentos que terão como destino o lixo comum.

Gasparini, Gasparini e Frigieri (2011) afirmam que os medicamentos são essenciais para a manutenção da saúde da população, porém, a mídia dá um grande incentivo ao consumo excessivo de medicamentos e isso, aliado ao problema da automedicação $^{5}$, faz aumentar o acúmulo de medicamentos não utilizados nas residências.

Para Jesus (s.d.,p.07):

O alto índice de automedicação da população brasileira também tem forte relação com o mercado ocupado pela indústria farmacêutica. A indústria utiliza estratégias criativas por meio das ferramentas de marketing e das propagandas no mercado farmacêutico. A propaganda exerce forte influência sobre o consumidor, fazendo com que ele adquira produtos ou serviços sob pressões internas (usos e costumes) e externas(informações inadequadas), que deformam o contrato de consumo, tornando-o não mais um ato voluntário, mas sim um ato condicionado.

Segundo Bidone (2005) a incineração de resíduos sólidos seria o destino adequado para os medicamentos que necessitam ser descartados, pois é um processo de oxidação à alta temperatura que destrói ou reduz o volume ou recupera materiais ou substâncias, ou seja, transformar os rejeitos em materiais inertes, reduzindo peso e volume.

Porém, no entender de Alvarenga e Nicoletti (2010) não se deve deixar de considerar que a incineração por sua vez gera emissão de gases tóxicos à atmosfera.

No entender de Silva (2005) para tentar solucionar a questão da quantidade de lixo, propõe uma mudança no comportamento social, principalmente nos padrões de produção e consumo com a diminuição de medicamentos descartados.

\footnotetext{
${ }^{5}$ Atualmente a automedicação no Brasil é um caso sério de saúde pública, que leva muitas pessoas à intoxicação, por vezes, à morte. Como se não bastasse o poder da indústria farmacêutica em altos investimentos de marketing e na propaganda, ela encontra como parceira: médicos e a mídia de massa, que legitima algumas informações e divulga muitas vezes, sem responsabilidade, medicamentos a leigos, o que estimula o consumo irracional. (JESUS, s.d.,p.11)
} 
De acordo com a Resolução $n^{\circ} 44$ de 17 de agosto de 2009, a Agência Nacional de Vigilância Sanitária (Anvisa) dispõe no artigo 93 que fica permitido às farmácias e drogarias participarem de programas de coleta de medicamentos (nos moldes do que comumente chamamos de Logística Reversa ${ }^{6}$ ) a serem descartados pela comunidade com o intuito de preservar a saúde pública e a qualidade do meio ambiente, porém, não há legislação especifica para cobrar desses estabelecimentos à realização destas campanhas, atribuindo então a responsabilidade para a comunidade em devolver a esses lugares os medicamentos não utilizados.

Entretanto, conforme a legislação brasileira, as farmácias não têm a obrigação de receber remédios que não serão mais usados.

Em relação aos postos de saúde, os mesmos não podem aceitar os medicamentos para repasse entre usuários, mesmo dentro da data de validade, uma vez que não é possível controlar e saber como eles foram armazenados durante o período que ficaram fora da unidade de saúde.

Assim, os órgãos de saúde sabem que o problema existe, mas, pouco é feito para solucioná-lo. As normas existentes dizem respeito aos estabelecimentos de serviços de saúde, porém, ainda não foram editadas normas que abranjam o consumidor final com relação ao descarte de medicamentos, pois a Constituição Federal de 1988 atribui, aos estados e municípios, autonomia para criarem as próprias leis que estabeleçam a forma correta de descarte de medicamentos e suas sobras.

\section{CONSIDERAÇÕES FINAIS}

Para evitar a ocorrência do uso e descarte inadequado de medicamentos, população e governantes devem atuar de forma conjunta para a solução desse grave problema ambiental, através da criação de pontos para coleta dos remédios para serem encaminhados ao descarte adequado, passando, assim, a ser

\footnotetext{
${ }^{6}$ Logística reversa é o processo de planejamento, implementação e controle do fluxo dos resíduos de pós-consumo e pós-venda e seu fluxo de informação do ponto de consumo até o ponto de origem, com o objetivo de recuperar valor ou realizar um descarte adequado. Disponível em:< http://www.abrepet.com.br/log reversa.html>. Acesso em 05/09/2014.
} 
responsabilidade das farmácias e drogarias a destinação também desses medicamentos. Esta medida é esperada a partir da definição e implementação, pela ANVISA, do Acordo Setorial de Implantação da Logística Reversa de Resíduos de Medicamentos, dentro da Política Nacional de Resíduos Sólidos.

A formação de parcerias entre laboratórios farmacêuticos e redes de drogarias seria uma opção para captar os medicamentos dispensados pela população e oferecer um descarte adequado.

A informação e o acesso à mesma acerca dos riscos ao meio ambiente e à saúde pública passam a ser um marco necessário para, a partir de campanhas educacionais, mobilizar a população em geral para a redução da quantidade de medicamentos descartados.

Tal conscientização por parte da população passa, necessariamente, por algumas mudanças de hábito como a compra da quantidade necessária ao tratamento a partir da efetivação da venda fracionada de medicamentos em farmácias e drogarias.

Outro item de extrema importância decorre da orientação quanto ao acondicionamento adequado dos mesmos nas residências e a procura por postos de coleta, no momento do descarte, com ampla divulgação à população em geral.

\section{REFERÊNCIAS}

ALVARENGA, L.S.V./ NICOLETTI, M.A. Descarte Doméstico de Medicamentos e algumas considerações sobre o Impacto Ambiental. Revista Saúde, 2010.

BIDONE, F. A. Resíduos Sólidos Provenientes de Coletas Especiais: Eliminação e Valorização. 2005. Disponível em:<http://www.finep.gov.br/prosab/livros/ prosabbidonefinal.pdf>. Acesso em: 04.06.2012.

BRASIL. Resolução da Diretoria Colegiada n 44, 17 de agosto de 2009. Brasília, DF: [s.n], 2009. Disponível em:<http://www.crfsp.org.br/joomla/index.php?option=com_content\&view=article\&id=1696:resolucaordc-no-44-de-17-de-agosto-de-2009-\&catid=113:legislacao>>. Acesso em: 14 fev. 2010.

GASPARINI, J.C.; GASPARINI, A. R.; FRIGIERI, M.C. Estudo do descarte de medicamentos e consciência ambiental no município de Catanduva-SP. $2011 . \quad$ Disponível em:<http://www.fatecjab.edu.br/revista/2011_v02_n01/4_gasparini.pdf >. Acesso em 13 de outubro de 2011. 
JESUS, O. R. C. de. O consumo desenfreado de medicamentos no Brasil e a responsabilidade da propaganda. s.d. Disponível em:<

http://www2.metodista.br/unesco/1 Ecom\%202012/GT4/32.0\%20consumo\%20desenfreado Paula\%2 0Jesus.pdf>. Acesso em 05/09/2014.

NASCIMENTO, C. E . Descarte de Remédios: uma questão muito grave. 2008. Disponível em: <htp://planetasustentavel. abril.com.br/noticia/lixo/conteudo_296191.shtml>. Acesso em 15 de outubro de 2011.

RODRIGUES, C. R. B. Aspectos Legais e Ambientais do Descarte de Resíduos de Medicamentos. Disponível em:<http:// www.pg.utfpr.edu.br/dirppg/ppgep/dissertacoes/arquivos/121/Dissertacao.pdf>.Acessso em 22 de setembro de 2011.

SILVA, E. R. Problematizando o Descarte de Medicamentos Vencidos: para onde destinar? 2005. Disponível em: <http://www.epsjv.fiocruz.br/beb/Monografias2005/evelyn.pdf>. Acesso em: 05/06/2012.

SOTORIVA, P. Descarte Incorreto de Medicamentos Ameaça o meio Ambiente. 2009. Disponível em: < http://www.medicsupply.com.br/pacientes/blog/descarteincorretodemedicamentosameaca- meioambiente/>. Acesso em: 05/06/2012. 